\title{
Sequential Auctions, Price Trends, and Risk Preferences
}

Audrey Hu*

Liang Zou

Faculty of Economics and Business, University of Amsterdam, the Netherlands.

* Tinbergen Institute, the Netherlands 
Tinbergen Institute is the graduate school and research institute in economics of Erasmus University Rotterdam, the University of Amsterdam and VU University Amsterdam.

More TI discussion papers can be downloaded at http://www.tinbergen.nl

Tinbergen Institute has two locations:

Tinbergen Institute Amsterdam

Gustav Mahlerplein 117

1082 MS Amsterdam

The Netherlands

Tel.: +31(0)205251600

Tinbergen Institute Rotterdam

Burg. Oudlaan 50

3062 PA Rotterdam

The Netherlands

Tel.: +31(0)10 4088900

Fax: $+31(0) 104089031$

Duisenberg school of finance is a collaboration of the Dutch financial sector and universities, with the ambition to support innovative research and offer top quality academic education in core areas of finance.

DSF research papers can be downloaded at: http://www.dsf.nl/

Duisenberg school of finance

Gustav Mahlerplein 117

1082 MS Amsterdam

The Netherlands

Tel.: +31(0)20 5258579 


\title{
Sequential Auctions, Price Trends, and Risk Preferences
}

\author{
Audrey $\mathrm{Hu}$ \\ University of Amsterdam/Tinbergen Institute \\ Liang Zou \\ University of Amsterdam
}

October 15, 2014 


\title{
Sequential Auctions, Price Trends, and Risk Preferences
}

\begin{abstract}
We analyze sequential auctions where bidders are heterogeneous in risk exposures and exhibit non-quasilinear utilities. We derive an increasing pure strategy equilibrium for the sequential Dutch and Vickrey auctions with arbitrary number of identical objects for sale. A sufficient, and to certain extent necessary, condition for this result is that bidders' marginal utilities are log-submodular in income and type. This condition is fairly general, and in the environment we consider implies that both the Dutch and Vickrey sequential auctions are ex post efficient. We then show that when bidders are risk averse (preferring), the equilibrium price sequences must be downward (upward) drifting. In particular, the "declining price anomaly" is perfectly consistent with nonincreasing absolute risk aversion when bidders have exposures to background risks - that is, when failure of acquiring the auctioned object entails negative consequences.
\end{abstract}

Key words: sequential auction, background risk, risk preferences, declining prices, log-submodularity, ex post efficiency

JEL classification: D44, D82 


\section{Introduction}

Sequential auctions frequently take place to sell multiple units of similar objectsone after another - using the same auction policy. Examples range from fine wine, cut flowers, live cattle, licenses, mineral rights to blocks of shares of IPO firms or the like. Bidders at these auctions are typically business people to whom both winning and losing can have risky consequences. For example, it can be a firm bidding for an asset to diversify its ongoing risk, or a wholesaler for roses to supply foreign demand and so on. In these situations, a bidder's willingness-to-pay can be directly related to the severity of the undesirable consequences should he lose, as well as the added value should he win. We construe these situations as bidders having exposures to background risk!

Indeed, as Arrow (1951, p.404) put it: "Risk and the human reactions to it have been called upon to explain everything from the purchase of chances in a 'numbers' game to the capitalist structure of our economy; according to Professor Frank Knight, even human consciousness itself would disappear in the absence of uncertainty." Few people would dispute this classical view. Yet, to date, most of the literature on sequential auctions has been focused on risk neutral bidders, or risk-free payoffs of the bidders upon winning or losing. Important issues as to how bidders' risk preferences would affect competitive bidding strategies, behavior of price patterns, and ex post efficiency in a sequential auction remain highly conjectural. In this paper, we take a serious look at these problems.

We consider a general model of sequential auctions in which bidders can have privately known exposures to risk, both before and after the auctions, and can be risk averse, risk neutral, or risk preferring. We focus on a sequence of Dutch

\footnotetext{
${ }^{1}$ Some studies allow bidders to have exposures to ensuing risk, or ex post risk, upon winningi.e., the true value of the object, or its contribution to the bidder's payoff, remains uncertain when the auction concludes (e.g., Maskin and Riley, 1984; Eso and White, 2004; Hu, Matthews and Zou, 2014; and Hu, Offerman and Zou, 2014). Our notion of background risk incorporates ensuing risk as a special case, but in general also allows losing bidders to face undesirable risky consequences.
} 
or Vickrey auctions with an arbitrary number $m$ of identical objects for sale to $n$ $(>m)$ competing bidders, each having a unit demand (e.g., Milgrom and Weber, 2000). As McAfee and Vincent (1993) demonstrate, the general $m$-unit sequential auctions are complicated when bidders exhibit risk aversion. Unlike single-unit auctions, in sequential auctions bidders have the option to buy the object in any period of the auctions and therefore a new dimension of strategic decision arises: now or later? The rational trade-off calls on a bidder to weigh his utility of winning in the current auction against the expected utility of winning in the subsequent auctions - given the bid history, the bidder's future plan, and the equilibrium play of the others. Risk aversion complicates such a trade-off and, as shown in McAfee and Vincent (1993), in the standard symmetric private values model the existence of a pure strategy equilibrium rests on an uncommon assumption that bidders exhibit nondecreasing absolute risk aversion (NDARA). Therefore, in the more commonly assumed environments where bidders exhibit nonincreasing absolute risk aversion (NIARA), any equilibrium has to involve mixed strategies that are ex post inefficient. McAfee and Vincent (1993) obtained these results assuming bidders are risk averse, private values are riskless, and there are two units for sale. The case beyond two units is left open because of the difficulty in establishing equilibria for $m$-period auctions even under the NDARA preferences.

A contribution of this paper is to show that the existence of a pure strategy equilibrium hinges on a key assumption that bidders' marginal utilities are logsubmodular in income and type. This condition is fairly general, as it imposes no restriction on the sign of the Arrow-Pratt measure of absolute risk aversion of the utility functions. The main contribution of our study is to derive and characterize a unique pure strategy equilibrium, in both the Dutch and the Vickrey sequential auctions, for the general $m$-period case (Propositions 1 and 2). Therefore, in the general environment considered in this paper, both the Dutch and the Vickrey sequential auctions are ex post efficient. The clear characterizations of the equilibria also allow us to obtain sharp predictions in terms of the expected price trends for 
risk neutral, risk averse, and risk preferring bidders (Proposition 3). A finding of particular interest is that there exists plausible situations (see Section 6), in which the well-known "declining price anomaly" is consistent with the common assumption that bidders exhibit NIARA.

Popularized by Ashenfelter's (1989) documentation of the "afternoon effect" in wine auctions, the "declining price anomaly" remains a lively issue of much academic attention. The "anomaly" refers to the empirical observations of downward-drifting price patterns for similar objects sold in sequential auctions. ${ }^{2}$ It contradicts the standard theoretical prediction that the expected prices should be the same when bidders have private values, or increasing when bidders' valuations are affiliated (e.g., Milgrom and Weber, 1981, 2000; Weber, 1983). Ashenfelter (1989, p.31) suggests that risk aversion lies at the bottom of the declining price anomaly: "Indeed, assuming bidders are risk averse may simply be a convenient analytical device for dealing with the fact that many bidders at auctions are buying to fill orders.... Theoretical work on auctions will almost certainly have to remove the assumption of risk neutral bidders if it is to explain the full range of interesting empirical results from real auctions." Intuitively, risk averse bidders are willing to pay a premium for removing the risk of losing in subsequent rounds of the auctions. As such, they can be comfortable upon winning even if the expected subsequent prices are lower than what they pay. Unfortunately, this logic is blurred under the observation of McAfee and Vincent (1993) that it rests on the assumption of NDARA in the standard private values models. A good number of papers have since emerged seeking different institutional details that may rationalize the declining price phenomenon in the risk neutral paradigm $?^{3}$ More recently, Mezzetti (2011) derived a declining price result

\footnotetext{
${ }^{2}$ For example, see Ashenfelter (1989), Ashenfelter and Genesove (1992); Beggs and Graddy (1997); McAfee and Vincent (1993); Van den Berg, Van Ours and Pradhan (2001); among others.

${ }^{3}$ See, e.g., Black and De Meza (1992); McAfee and Vincent (1997); Bernhardt and Scoones (1994); Engelbrecht-Wiggans (1994); Gale and Hausch (1994); Menezes and Monteiro (2003); Von
} 
in sequential auctions assuming that bidders are averse only to the risk of price they pay $y^{4}$ In Section 2, we discuss how the models of McAfee and Vincent (1993) and Mezzetti (2011) for his private-values case are generalized in our environment. The general conclusions concerning the price trends from our study are that when bidders are risk averse, the expected price in both the sequential Dutch and Vickrey auctions declines over time in the course of the sale and when bidders are risk preferring $5^{5}$ the price trend is reversed $!^{6}$

In Section 2, we present the model and the assumption of log-submodularity on the bidders' marginal utilities. A number of special cases that are of interest are shown to be consistent with this assumption. We then analyze the sequential Dutch auctions in Section 3, showing that it is ex post efficient as a consequence of the existence of a unique pure strategy equilibrium. Section 4 derives and characterizes the unique pure strategy equilibrium for the sequential Vickrey auctions, arriving at the same conclusion that the auctions are ex post efficient. Section 5 shows how bidders' risk attitudes predict the behavior of price sequences. Section 6 discusses background risk and explains why a marginal utility function that satisfies logsubmodularity can be derived from a primitive utility function that exhibits NIARA. Section 7 concludes the paper with some remarks on future research. Appendix A der Fehr (1994); Jeitschko (1999); Gale and Stegeman (2001); Pitchick and Schotter (1988); Beggs and Graddy (1997); Ginsburgh (1998); Eyster (2002); Kittsteiner et al. (2004); and Mezzetti (2011), among others.

${ }^{4}$ Mezzetti (2011) also considered affiliated values and a non-standard formulation of English auctions, with mixed results.

${ }^{5}$ Risk seeking preferences can be due to bidders financing their bids with borrowed money, or firms with existing debt that act to maximize the equity values of shareholders. Then, limited liability could lead to a convex payoff function and cause a bidder to behave like he is risk preferring (see, e.g., the single-unit auction models of Zheng, 2001; DeMarzo, Kremer and Skrzypacz, 2005; Board, 2007).

${ }^{6}$ Increasing price patterns are observed empirically in, e.g., Delas and Kosmopoulou (2004); Chanel et al. (1996); Jones et al. (2004); and Gandal (1997). 
presents several useful properties that are implications of log-submodular marginal utilities, and Appendix B contains the proofs of the propositions.

\section{Environment}

A number $m(\geq 1)$ of identical objects are for sale sequentially, one at a time through periods $1, \ldots, m$ using either an open descending Dutch auction throughout, or a Vickrey auction throughout. There are $n(>m)$ competing bidders at the start, each having a single-unit demand for the object.

In each period $k$ of the Dutch auction, the price of an item steadily declines from a very high level until one of the bidders indicates that he is willing to pay. The bidder then becomes the winner of the $k$ th auction and purchases the object at his stopping price. Because of the open format of the Dutch auction, the winning price in each period is publicly observed. The Dutch auction is thus strategically equivalent to a first-price sealed-bid auction with the announcement of the winning price in each period.

In each period $k$ of the Vickrey auction (or, equivalently, the second-price sealed-bid auction), the active bidders submit sealed bids and the highest bidder wins and pays the price equal to the second highest bid. Because of the sealedbid policy, we assume that the remaining active bidders do not know the winning prices. However, in deriving the equilibrium strategies we will first assume that the winning bid is announced in each period, and then show that the announcement of the winning bid has no effect on the bidding strategies. This is the standard approach that simplifies the equilibrium analysis.

In both Dutch and Vickrey auctions, we assume that if several bidders are tied in any period $k$ with the same highest bid, then all of them will buy the remaining objects at their bid. If the remaining number of objects falls short of the number of the tied bidders, then the allocation will be resolved randomly and the auction concludes. The reserve price in each period is normalized to be zero, and if a bidder 
does not win, he pays zero.

Each bidder $i$ has a private type $t_{i} \in[0,1]$ that affects his preference for the object. Ex ante, the types $t_{i}$ are independently distributed according to the same cumulative distribution $F$ with $F(0)>d^{7}$ and density $f=F^{\prime}$ that is strictly positive and continuous on $[0,1]$.

The preference of a typical bidder with type $t$ is represented by

$$
\left\{\begin{array}{lc}
w(x, t) & \text { if he wins the object and receives income } x \\
u(x, t) & \text { if he loses and receives income } x
\end{array}\right.
$$

We interpret $w: \mathbb{R} \times[0,1] \rightarrow \mathbb{R}$ and $u: \mathbb{R} \times[0,1] \rightarrow \mathbb{R}$ as the bidder's (induced) utilities conditional on winning and losing, respectively. In particular, $u(\cdot, t)$ is type- $t$ bidder's status-quo utility for income, and a losing bidder after all objects are sold will have a utility denoted by $u(0, t)$. The preference model in (1) generalizes Maskin and Riley (1984) by allowing the private type $t$ of a bidder to matter in both winning and losing events. This generalization is particularly useful for incorporating background risks in our analysis.

We assume that $u$ and $w$ are twice continuously differentiable. In addition, the following assumptions will be maintained throughout the paper.

Assumption 1 The partial derivatives $w_{1}(x, t)>0$ and $w_{2}(x, t)>u_{2}(0, t)$ for all $x$ and $t$ such that $w(x, t) \geq u(0, t)$.

Assumption $2 w_{1}(x, t)$ is log-submodular in $(x, t)$ for all $x$ and $t$ such that $w(x, t) \geq$ $u(0, t)$.

Assumption 1 provides the standard condition that utility increases in income, and a higher type makes a winning bidder better off as long as he prefers winning over losing. It is important to point out that no restriction is made on the signs of the partial derivatives $u_{2}(0, t)$ and $w_{2}(x, t)$.

\footnotetext{
${ }^{7}$ This is a mild assumption consistent with situations where the seller has a reserve price that is (slightly) higher than the lowest willingness-to-pay of the bidder types. See footnote 11.
} 
A positive bivariate function $h(x, y)$ is log-submodular (log-supermodular) in $(x, y)$ if and only if for all $x<x^{\prime}$ and $y<y^{\prime}$ (e.g., Topkis, 1978, Milgrom and Weber, 1982; Jewitt, 1987; Athey, 2001, 2002),

$$
h\left(x^{\prime}, y^{\prime}\right) h(x, y) \leq[\geq] h\left(x^{\prime}, y\right) h\left(x, y^{\prime}\right)
$$

Therefore, Assumption 2 is equivalent to the assumption that $w_{1}(-x, t)$ is $\log$ supermodular in $(x, t)$. Obviously, this assumption holds trivially true if $w$ is quasilinear in $x$. For a general function $w$, we summarize in Appendix A some of its useful properties when its partial derivative $w_{1}(x, t)$ is log-submodular.

For ease of exposition, the following lemma provides three equivalent statements in terms of log-submodular/log-supermodular marginal utilities and nonincreasing/nondecreasing absolute risk aversion of a von Neumann-Morgenstern utility function. The proof of the lemma amounts to straightforward verifications, and is thus omitted (see, e.g., Athey, 2001 for part (iii) of the lemma).

Lemma 1 Let $U$ be a von Neumann-Morgenstern utility function with $U^{\prime}>0$. Then the following three conditions are equivalent:

(i) $U(x)$ exhibits nonincreasing [nondecreasing] absolute risk aversion 8

(ii) $U^{\prime}(x-y)$ is log-submodular [log-supermodular] in $(x, y)$.

(iii) $U^{\prime}(x+y)$ or $U^{\prime}(-x-y)$ is log-supermodular [log-submodular] in $(x, y)$.

Our environment incorporates many special cases of interest. For example, consider the following four.

Case 1. $u(0, t) \equiv U(0)$ and $w(x, t)=U(v(t)+x)$, with $v^{\prime}(t)>0$.

This is the standard private values model that has been extensively studied, including McAfee and Vincent (1993). Because $v^{\prime}>0$, by Lemma $1 w_{1}(x, t)$ is logsubmodular if and only if $U$ exhibits NDARA, a condition required by McAfee and Vincent for the existence of a pure strategy symmetric equilibrium in their sequential first-price and second-price auctions.

\footnotetext{
${ }^{8}$ That is, without restricting to risk aversion.
} 
Case 2. $u(0, t) \equiv U(0)$ and $w(x, t)=U(v(t)+\varphi(x))$, with $v^{\prime}(t)>0$, and $\varphi^{\prime}(x)>0$.

In this case, the object is of certain quality $v(t)$ that contributes to the utility. But the object may not have an equivalent monetary value. This is Case 2 of Maskin and Riley (1984). For $U$ risk neutral, define $\ell(p)=-\varphi(-p)$ and assume $\ell^{\prime \prime}=-\varphi^{\prime \prime} \geq 0$. Then $w(-p, t)=v(t)-\ell(p)$ and the model reduces to Mezzetti (2011) for his private-values case. The partial derivative $w_{1}(-p, t)=\ell^{\prime}(-p)$ is independent of $t$, so that (2) holds as an equality. This shows that Mezzetti's private-values model satisfies Assumption 2 and is therefore nested as a special case of our environment. For $U$ nonlinear, Assumption 2 continues to hold for the NDARA class of functions $U$.

Case 3. $u(0, t) \equiv 0$ and $w(x, t)=\int \max (v+x-B, 0) d Q(v \mid t)$, where a higher $t$ shifts $Q$ to the right in the sense of first-order stochastic dominance.

This case captures the effect of limited liability, where $B$ can be interpreted as the bidder's liability or face value of debt. Because $w$ is now convex in $x$, we have $w_{11}>0$ so the bidder's induced utility $w$ is risk preferring. Suppose the density $Q_{1}(v \mid t)$ exists and is positive on the support of $v$. Then it can be readily verified that Assumption 2 holds if the hazard rate $\left(1-Q(v \mid t) / Q_{1}(v \mid t)\right.$ is nondecreasing in $t$ (e.g., Board, 2007).

Case 4. A bidder's income $v$ has a distribution $Q(v \mid t)$ if losing and $\hat{Q}(v \mid t)$ if winning, i.e.,

$$
\begin{aligned}
u(0, t) & =\int_{-\infty}^{\infty} U(v) d Q(v \mid t) \\
w(x, t) & =\int_{-\infty}^{\infty} U(v+x) d \hat{Q}(v \mid t) \text { with } \hat{Q}_{2}(v \mid t)<Q_{2}(v \mid t)
\end{aligned}
$$

Winning allows the bidder to realize a more favorable income distribution $\hat{Q}(v \mid t)$, which dominates his status-quo income distribution $Q(v \mid t)$ in the sense of first-order stochastic dominance. We say that a bidder is exposed to background risk if $u(0, t)$ cannot be "normalized" as zero without losing generality. So Case 4 allows 
the bidder to have exposures to both ensuing risk, since $v$ remains uncertain to the winner, and background risk. We will take a closer look at this case in Section 6.

\section{Sequential Dutch Auctions}

We first look at the Dutch auctions. At the start, a bidding strategy for a bidder with type $t$ is a collection of $m$ bid functions $b_{1}, \ldots, b_{m}$ where $b_{k}\left(t \mid p_{1}, \ldots, p_{k-1}\right)$ denotes his bid in the $k$ th auction, given that he has lost the previous $k-1$ auctions and observed the winning prices $p_{1}, \ldots, p_{k-1}$. We focus on symmetric pure strategy equilibria in which $b_{k}$ is a continuous and increasing function of the bidder's type $t$. The collection of strategies $\left\{b_{k}, k=1, \ldots, m\right\}$ is a symmetric equilibrium of the sequential auctions game if in any period $k$, every active bidder finds it optimal to play $b_{k}$-given that the other active bidders play strategy $b_{k}$, and that all bidders, including the bidder himself, plan to play the remaining strategies $\left\{b_{\ell}, \ell=k+1, \ldots, m\right\}$ upon losing the $k$ th auction.

For $b_{k}$ continuous and increasing in $t$, as will be verified, in equilibrium the winning bidder's type in each auction is revealed to the remaining active bidders. By symmetry, w.l.o.g. we focus on analyzing the optimal strategies of bidder 1. Let the random variable $Y_{k}$ denote the $k$ th highest type from among the $n-1$ bidders other than bidder 1 , so that if bidder 1 with type $t$ wins the $k$ th auction, in equilibrium it must be the case that

$$
Y_{k}<t<Y_{k-1}, \quad k=1, \ldots, m
$$

where $Y_{0}=\infty$ (by default). We let $F_{k}\left(\cdot \mid y_{k-1}\right)$ denote the cumulative distribution, and $f_{k}\left(\cdot \mid y_{k-1}\right)$ the associated density function, of $Y_{k}$ conditional on $Y_{k-1}=y_{k-1}$. So, the conditional equilibrium expected payoff for bidder 1 when he lost the previous

\footnotetext{
${ }^{9}$ To ease analysis, we ignore the zero-probability events of ties, which will not affect the results of this paper.
} 
$k-1$ auctions and observed $y_{k-1}$, can be specified recursively for all $k$ by

$$
W_{I}^{k}\left(t \mid y_{k-1}\right):=w\left(-b_{k}(t), t\right) F_{k}\left(t \mid y_{k-1}\right)+\int_{t}^{y_{k-1}} W_{I}^{k+1}(t \mid y) d F_{k}\left(y \mid y_{k-1}\right),
$$

In (3), the first term on the right-hand side is associated with the winning event $Y_{k}<t<y_{k-1}$, and the last term the losing event $t<Y_{k}<y_{k-1}$. If the bidder loses in period $k<m$, he still has the chance to win in the subsequent period $k+1$ and hence attain the expected utility of $W_{I}^{k+1}$. The final period expected payoff is given by

$$
W_{I}^{m}\left(t \mid y_{m-1}\right)=w\left(-b_{m}(t), t\right) F_{m}\left(t \mid y_{m-1}\right)+u(0, t)\left(1-F_{m}\left(t \mid y_{m-1}\right)\right)
$$

where, for $m=1$, the equation reduces to the familiar specification of expected utility in single-unit first-price auctions.

Proposition 1 Under Assumptions 1 and 2, there exists a unique continuous and increasing symmetric equilibrium of the Dutch sequential auctions $\left\{b_{k}: k=1, \ldots, m\right\}$ characterized by

$$
\begin{aligned}
b_{m}^{\prime}(t) & =(n-m) \frac{w\left(-b_{m}(t), t\right)-u(0, t)}{w_{1}\left(-b_{m}(t), t\right)} \frac{f(t)}{F(t)} \\
b_{k}^{\prime}(t) & =(n-k) \frac{w\left(-b_{k}(t), t\right)-w\left(-b_{k+1}(t), t\right)}{w_{1}\left(-b_{k}(t), t\right)} \frac{f(t)}{F(t)}, k=1, \ldots, m-1
\end{aligned}
$$

with the initial conditions $b_{k}(0)=b_{0}$ that solves $w\left(-b_{0}, 0\right)=u(0,0)$.

The differential equation (5) derives from maximizing the expected payoff in (4), which is similar to the standard characterization of bidding strategy in the singleunit first-price auctions. Except for special cases (e.g. when w exhibits constant absolute or constant relative risk aversion), the strategy cannot be solved explicitly but Assumptions 1 and 2 ensure the existence of a unique $b_{m}$. For Cases 1-4, it can be readily verified that Assumption 2 is equivalent to $U(x)$ being log-concave for $m=1$. Therefore the characterization of $b_{m}$ in (5) can be seen as a generalization of the existing symmetric first-price private values auctions (e.g., Holt, 1980; Milgrom, 
2004, Chapter 4.3) in terms of the more general utility function $w$. The differential equations in (6) derive from maximizing (3), assuming sequentially rational best responses of every bidder to the bidding strategies of the others.

In general, consistent with the existing results under risk neutrality (e.g., Milgrom and Weber, 2000), bidders submit increasingly higher bids if they lose, i.e., the bid $b_{k}(t)$ increases as $k$ increases. Another noteworthy point, as can be seen from (5)-(6), is that the previous winning prices have no influence on the remaining active bidders' strategies.

In Proposition 1, Assumptions 1 and 2 are sufficient conditions that ensure the existence of a pure strategy equilibrium for arbitrary distribution functions $F$ in the general environment. If the result is to hold as such in general, then Assumptions 1 1, 2 also become necessary. For instance, McAfee and Vincent (1993) showed that for Case 1, if $U$ exhibits decreasing absolute risk aversion (DARA), or equivalently, if Assumption 2 is violated, then there may not exist a pure strategy equilibrium.

An important consequence of Proposition 1 is that the sequential Dutch auction is ex post efficient in this environment. Essential for this result is the existence of an increasing pure strategy equilibrium, which implies that all $m$ winners have higher willingness to pay than any of the losers do. In other words, when the auction concludes no re-trade among bidders could lead to a Pareto superior re-allocation.

\section{Sequential Vickrey Auctions}

We analyze in this section the sequential Vickrey auctions or its strategically equivalent format second-price sealed-bid auctions. In each period, the winning bidder pays the price of the second highest bid, and the losers pay nothing. Let $\left\{a_{k}: k=1, \ldots, m\right\}$ denote the collection of symmetric bid functions, and assume (and verify later) that each $a_{k}$ is a continuous and increasing function of type $t$. Following the literature, we assume that the winning bid, but not the winning price, is announced in each 
auction period. ${ }^{10}$ As it turns out however, similar to the Dutch auctions, in equilibrium the knowledge of the winning bid in each period has no effect on the active bidders' remaining strategies.

The equilibrium expected payoff for bidder 1 if he lost the previous $k-1$ auctions and observed $Y_{k-1}=y_{k-1}$, can be specified recursively for all $k$ by

$$
W_{I I}^{k}\left(t \mid y_{k-1}\right):=\int_{0}^{t} w\left(-a_{k}(y), t\right) d F_{k}\left(y \mid y_{k-1}\right)+\int_{t}^{y_{k-1}} W_{I I}^{k+1}(t \mid y) d F_{k}\left(y \mid y_{k-1}\right),
$$

where the first term on the right-hand side is associated with the winning event $Y_{k}<t<y_{k-1}$ in period $k$, and the last term the event $t<Y_{k}<y_{k-1}$, with the final period expected payoff given by

$$
W_{I I}^{m}\left(t \mid y_{m-1}\right)=\int_{0}^{t} w\left(-a_{m}(y), t\right) d F_{m}\left(y \mid y_{m-1}\right)+u(0, t)\left(1-F_{m}\left(t \mid y_{m-1}\right)\right)
$$

Proposition 2 Under Assumptions 1 and 2, there exists a unique continuous and increasing symmetric equilibrium of the Vickrey sequential auctions $\left\{a_{k}: k=\right.$ $1, \ldots, m\}$ satisfying

$$
\begin{aligned}
w\left(-a_{m}(t), t\right) & =u(0, t) \\
w\left(-a_{k}(t), t\right) & =\int_{0}^{t} w\left(-a_{k+1}(y), t\right) d F_{k+1}(y \mid t)
\end{aligned}
$$

The proposition shows that in every period $k$, the previous winner's type $y_{k-1}$ does not appear in (8) so that any realization of $Y_{k-1}$ has no influence on the subsequent equilibrium bids. Instead, the bidder calculates his expected subsequent period payoff using the distribution $F_{k+1}(y \mid t)$ of $Y_{k+1}$ conditional on the event $Y_{k}=t$.

The equation in (7) of the proposition provides the familiar (weakly) dominant strategy of bidding up to one's break-even level, when there is a single object left

${ }^{10}$ If the winning price is announced in each period, the situation resembles a sequence of open acending English auctions. As some of the pivotal or highest losing bidders will still be active, if their bids were known the existence of a pure strategy equilibrium can be difficult to establish. The conventional model of button-English auctions may become inappropriate as well. See, e.g., Mezzetti (2011). 
for sale. The equations (8) say about the same thing, although not in terms of dominant strategies: in the sequential Vickrey auction it is optimal to bid up to the level in each period $k$ such that the bidder is indifferent whether paying his bid and win or losing the $k$ th period of the auction. This reveals an interesting link between the private-values sequential Vickrey auction, as modelled here, and the single-unit Vickrey auction with affiliated values, as modelled in Milgrom and Weber (1982). In both models, it is optimal for a bidder to bid up to an amount such that he will be at tie with the next potential winner, i.e., $Y_{k}=t$.

In light of McAfee and Vincent's observation (1993, Remark 3) that for Case 1 , NDARA is necessary for the existence of a pure strategy equilibrium in a twounit second-price sequential auction, Assumption 2 can also be seen, to some extent, necessary for the result of Proposition 2.

Like the sequential Dutch auction, a desirable feature of the sequential Vickrey auction is that it is ex post Pareto efficient in this general environment.

\section{Price Trends}

The equilibrium strategies derived in Propositions 1 and 2 have clear-cut implications for the expected price trends, as well as the comparative revenues between the sequential Dutch and Vickrey auctions. We first show the price trends as consequences of bidders' risk preferences.

Proposition 3 Under Assumptions 1 and 2, let $p_{1}, \ldots, p_{m}$ be the prices that the objects are sold in periods $1, \ldots, m$ of the Dutch or Vickrey auctions, respectively. Then, for all $k=1, \ldots, m-1$,

(i) if $w_{11}<0$, then $E\left(\tilde{p}_{k+1} \mid p_{k}\right)<p_{k}$;

(ii) if $w_{11}=0$, then $E\left(\tilde{p}_{k+1} \mid p_{k}\right)=p_{k}$;

(iii) if $w_{11}>0$, then $E\left(\tilde{p}_{k+1} \mid p_{k}\right)>p_{k}$. 
The intuition of this proposition is that for risk averse bidders, the risk of losing outweighs the opportunity of winning in subsequent periods of the auction. Consequently, they are more eager to avoid the risk of losing and are thus willing to pay a risk premium for it. For risk preferring bidders, they value more the option of waiting and winning in subsequent periods, and are thus reluctant to bid too high in earlier rounds. As mentioned in the introduction, the risk averse case has been shown in McAfee and Vincent (1993) in a two-period model under the assumption of NDARA. Proposition 2 generalizes their conclusion and further shows the consequence of increasing price sequences when bidders are risk preferring.

\section{Background Risk}

As mentioned in the introduction, bidders in sequential auctions are conceivably more likely to be firms or individuals who have a business to run. A bidder's objective of acquiring the auctioned object can be just to maintain an ongoing business. Under these circumstances, participating in an auction can be motivated by either seeking potential profits or avoiding potential losses or both. For instance, losing in the auctions could mean losses of sales, customers, or any kind of unintended consequence that a bidder would like to avoid. Such background risk, as we call it, is perhaps inconsequential when bidders are risk neutral. In this case only the difference between winning and losing matters so that the status-quo utility of a bidder may be normalized as zero. However, when bidders are not risk neutral, such a normalization removes an important part of reality - that is, when winning helps reduce the background risks. Indeed, taking background risks into consideration significantly enlarges the scope of our theoretical predictions. In particular, it allows us to explain the "declining price anomaly" in sequential auctions under the common assumption that bidders exhibit nonincreasing absolute risk aversion (NIARA).

To gain some insight into this conclusion, let us compare the following two sim-

ple models. Consider first a symmetric private-values setting (e.g., Case 1) where 
bidders adopt an increasing equilibrium strategy in each period of a sequential auction. Suppose a bidder's utility with private value $v$ equals $U(v-p)$ if he wins at price $p$ and $U(0)=0$ if he loses. Then the highest-value bidder will win in the first period, the second-highest next, and so on. If bidders expect declining prices, then the early winners should be (weakly) more risk averse than the late winners (see McAfee and Vincent, 1993, Remark 3). This is the case when $U$ exhibits NDARA, so that for $v>\hat{v}, U(v+x)$ is (weakly) more risk averse than $U(\hat{v}+x)$ in $x$.

Consider next a similar setting except that the losing bidder has a statusquo utility $U(-C(v))$ where $C$ is some cost function that increases in $v$ (e.g., cost of losing sales or customers due to failure of delivering orders), and that winning removes that potential cost, generating a utility of $U(r-p)$ to the bidder (e.g., $r$ is the revenue, and $r-p$ is the profit when the object is purchased at price $p$ and sold). Then, the highest bid in the first period of the auction is still the one with highest $v$, but for the higher bids to come from bidders who are more risk averse than those submitting lower bids, by Lemma 1 the level of risk aversion of $U(x-C(v))$ as a function of $x$ has to be nonincreasing in $v$.

Now consider the more general Case 4. Let $U$ be a von Neumann-Morgenstern utility function with $U^{\prime}>0$, and suppose

$$
\begin{aligned}
u(0, t) & =\int_{-\infty}^{\infty} U(v) d Q(v \mid t) \text { with } Q_{2}(v \mid t)>0 \\
w(x, t) & =\int_{-\infty}^{\infty} U(v+x) d \hat{Q}(v \mid t) \text { with } \hat{Q}_{2}(v \mid t)<Q_{2}(v \mid t)
\end{aligned}
$$

The assumption $Q_{2}(v \mid t)>0$ in (9) implies that $u(0, t)$ is a decreasing function of $t$. This represents the situation where the bidder's willingness-to-pay is directly related to the severity of his background risk.

Corollary 1 For Case 4, suppose $U$ exhibits NIARA and the density $\hat{Q}_{1}(v \mid t)$ is logsubmodular in $(v, t)$. Then there exists a pure strategy equilibrium in the sequential Dutch and Vickrey auctions as characterized in Proposition 1 and Proposition 2. respectively. 
Proof. It suffices to show that $w_{1}(x, t)$ is log-submodular so that Assumptions 1 2 2 hold, as 10 implies $w_{2}>u_{2}$. To see this, let $y=-v$. Then $\hat{Q}_{1}(-y \mid t)$ is log-supermodular in $(y, t)$ by assumption. Also by assumption, and by Lemma 1 , $U(v+x)$ is log-supermodular in $(v, x)$, which is equivalent to $U(-y-x)$ being log-supermodular in $(x, y)$. Consequently,

$$
w_{1}(-x, t)=\int_{-\infty}^{\infty} U^{\prime}(v-x) \hat{Q}_{1}(v \mid t) d v=\int_{-\infty}^{\infty} U^{\prime}(-y-x) \hat{Q}_{1}(-y \mid t) d y
$$

is log-supermodular, or $w_{1}(x, t)$ log-submodular, in $(x, t)$. This derives from the fact that log-supermodularity is preserved under integration (see, e.g., Athey, 2002).

This corollary extends and clarifies the conclusion of McAfee and Vincent (1993) that NDARA preferences are necessary for the existence of pure strategy equilibria in sequential auctions. The corollary suggests that there are many plausible circumstances in which NIARA, rather than NDARA, leads to a pure strategy

equilibrium. The assumption of $\log$-submodular density $\hat{Q}_{1}(v \mid t)$ captures the essential feature of background risk: a higher type $t$ increases a bidder's willingness-to-pay because it makes losing more painful.

\section{Concluding Discussion}

This paper shows that the efficiency property of the standard single-unit private values auctions can be extended to a significantly richer context: bidders can have non-quasilinear utilities as well as heterogeneous exposures to risk, and there can be multiple $(m)$ identical objects for sale sequentially. The extension derives from the existence of a pure strategy increasing equilibrium in both the sequential Dutch and Vickrey auctions.

The key assumption underlying all results of this paper is that bidders' utilities exhibit log-submodularity in income and type. The special cases (Cases 1-4) demonstrate that this condition is fairly general. Hence, the results obtained in this paper are applicable to a large class of circumstances. A subset of these circumstances, 
which we leave with the reader to judge its significance, is where bidders have exposures to background risks. In these situations the "declining price anomaly" is, in fact, not an anomaly but a natural consequence of nonincreasing absolute risk aversion.

Conceivably, efficiency may be harder to achieve if bidders have interdependent willingness-to-pay and affiliated types or signals. This is an open issue. Further extensions of the results of this paper are needed before the issue can be addressed properly. In light of the preponderant evidence that risk matters in decision making, this paper provides a useful first step towards analyzing auctions involving dynamic strategic decisions and non-quasilinear utilities. The next step will be a generalization towards interdependent valuations and affiliated signals. Given the insights derived from the present study, we surmise that the key to finding and solving pure strategy equilibria in the more general settings still hinges upon the assumption of log-submodular marginal utilities. This conjecture is left for future research.

Another line of future research concerns experimental testing of the results reported in this paper. As is well known, for single-object auctions, comparing results across experiments requires replicating the experimental conditions, which is not an easy task. The sequential auctions results, on the other hand, derive from a multi-period single sale with the same pool of bidders. As a result, the statistics and their relations to the primitive conditions observed during a sequential auction can be much amenable to experimental testing.

\section{Appendix A. Implications of Assumptions 1 and 2}

In this appendix we summarize five useful properties that are implications of Assumptions 1 and 2 .

Property 1. Assumptions 1 and 2 imply

$$
\frac{w(x, t)-w(y, t)}{w_{1}(x, t)} \leq \frac{w\left(x, t^{\prime}\right)-w\left(y, t^{\prime}\right)}{w_{1}\left(x, t^{\prime}\right)}, \forall t<t^{\prime} \text { and } \forall x, y
$$


This derives from (2) straightforwardly by integrations. Note that in (11), the signs of $x, y$, and $x-y$ are arbitrary.

Property 2. Assumptions 1 and 2 imply that for all $t<t^{\prime}$, and $x$ such that $w(x, t)>u(0, t)$,

$$
\frac{w(x, t)-u(0, t)}{w_{1}(x, t)} \leq \frac{w\left(x, t^{\prime}\right)-u\left(0, t^{\prime}\right)}{w_{1}\left(x, t^{\prime}\right)}, \forall t<t^{\prime}
$$

To see this, define $a(t)$ by $w(-a(t), t)=u(0, t)$. Then 12$)$ is equivalent to

$$
\frac{w(x, t)-w(-a(t), t)}{w_{1}(x, t)} \leq \frac{w\left(x, t^{\prime}\right)-w\left(-a\left(t^{\prime}\right), t^{\prime}\right)}{w_{1}\left(x, t^{\prime}\right)}, \forall t<t^{\prime}
$$

By Assumptions 1,

$$
a^{\prime}(t)=\frac{w_{2}(-a(t), t)-u_{2}(0, t)}{w_{1}(-a(t), t)}>0
$$

So (11) implies that $(w(x, t)-w(-a(t), t)) / w_{1}(x, t)$ is an increasing function of $t$.

Property 3. Property 1 implies that for all random $\tilde{y}$ such that $E w(\tilde{y}, t)$ exists (replace $y$ by $\tilde{y}$ and take expectation over $\tilde{y}$ in (11)),

$$
\frac{w(x, t)-E w(\tilde{y}, t)}{w_{1}(x, t)} \leq \frac{w\left(x, t^{\prime}\right)-E w\left(\tilde{y}, t^{\prime}\right)}{w_{1}\left(x, t^{\prime}\right)}, \forall t<t^{\prime} \text { and } \forall x
$$

Therefore, (11) has an economic interpretation that increasing $t$ makes the utility function $w(x, t)$ (weakly) more risk averse in income $x$.

Property 4. Suppose (11) holds, then

$$
w(x, t)=E w(\tilde{y}, t) \text { implies } w_{2}(x, t) \geq E w_{2}(\tilde{y}, t)
$$

This result is well known (e.g., McAfee and Vincent, 1993 and the references therein).

Property 5. Assumptions 1 and 2 imply

$$
\frac{w(x, t)-w(y, t)}{w_{1}(x, t)}\left\{\begin{array}{l}
>x-y \text { if } w_{11}<0 \\
=x-y \text { if } w_{11}=0 \\
<x-y \text { if } w_{11}>0
\end{array}\right.
$$

This can be seen by letting $w\left(x, t_{0}\right)$ denote a risk neutral utility function in $x$, so that $w\left(x, t_{0}\right)=h\left(t_{0}\right) x+g\left(t_{0}\right)$. Then, (15) follows as special cases of (11) because (13) implies $w_{11}(\cdot, t) \leq[\geq] 0$ iff $t \geq[\leq] t_{0}$. 


\section{Appendix B. Proofs of Propositions}

Proof of Proposition 1. We analyze by backward induction bidder 1's optimal response assuming that all others play a given set of continuous and increasing strategies $\left\{b_{k}: k=1, \ldots, m\right\}$. We take the standard approach by first assuming for each $k$ that $b_{k}^{\prime}>0$, and then verify that this is indeed true upon establishing its existence. In the last period, suppose bidder 1 has lost the preceding $m-1$ auctions and observed $Y_{m-1}=y_{m-1}$. The bidder's expected payoff if he has type $t$ and bids as though his type was $z$ equals

$$
V^{m}\left(z, t \mid y_{m-1}\right):=w\left(-b_{m}(z), t\right) F_{m}\left(z \mid y_{m-1}\right)+u(0, t)\left(1-F_{m}\left(z \mid y_{m-1}\right)\right)
$$

Taking partial derivative w.r.t. $z$ gives

$$
\begin{aligned}
& V_{1}^{m}\left(z, t \mid y_{m-1}\right) \\
= & -b_{m}^{\prime}(z) w_{1}\left(-b_{m}(z), t\right) F_{m}\left(z \mid y_{m-1}\right)+\left(w\left(-b_{m}(z), t\right)-u(0, t)\right) f_{m}\left(z \mid y_{m-1}\right) \\
= & \left.w_{1}\left(-b_{m}(z), t\right) F_{m}\left(z \mid y_{m-1}\right)\left(\frac{w\left(-b_{m}(z), t\right)-u(0, t)}{w_{1}\left(-b_{m}(z), t\right)} \frac{f_{m}\left(z \mid y_{m-1}\right)}{F_{m}\left(z \mid y_{m-1}\right)}-b_{m}^{\prime}(z)\right\rangle 17\right)
\end{aligned}
$$

As we do not assume that bidder 1 has followed the equilibrium strategies previously, there are two possibilities: $t<y_{m-1}$ and $t>y_{m-1}$. We first assume $t<y_{m-1}$, which is a consequence of equilibrium play given increasing bid functions $b_{k}$. Since $b_{m}^{\prime}>0$, from (17) it can be seen that if $V_{1}^{m}\left(z, t \mid y_{m-1}\right) \geq 0$ then $w\left(-b_{m}(z), t\right)>u(0, t)$. By (12) in Appendix A, $V_{1}^{m}\left(z, t \mid y_{m-1}\right) \geq 0$ thus implies

$$
\frac{w\left(-b_{m}(z), t\right)-u(0, t)}{w_{1}\left(-b_{m}(z), t\right)} \leq \frac{w\left(-b_{m}(z), t^{\prime}\right)-u\left(0, t^{\prime}\right)}{w_{1}\left(-b_{m}(z), t^{\prime}\right)} \text { for all } t^{\prime}>t
$$

and therefore $V_{1}^{m}\left(z, t^{\prime} \mid y_{m-1}\right) \geq 0$ for all $t^{\prime}>t$. Consequently, $V^{m}\left(z, t \mid y_{m-1}\right)$ satisfies the single-crossing condition of Milgrom and Shannon (1994) and the existence of $b_{m}$ is guaranteed under the assumption that $b_{m}$ is nondecreasing (e.g., Athey, 2001). From (17), $V_{1}^{m}\left(t, t \mid y_{m-1}\right)=0$ implies (5):

$$
\begin{aligned}
b_{m}^{\prime}(t) & =\frac{w\left(-b_{m}(t), t\right)-u(0, t)}{w_{1}\left(-b_{m}(t), t\right)} \frac{f_{m}\left(t \mid y_{m-1}\right)}{F_{m}\left(t \mid y_{m-1}\right)} \\
& =(n-m) \frac{w\left(-b_{m}(t), t\right)-u(0, t)}{w_{1}\left(-b_{m}(t), t\right)} \frac{f(t)}{F(t)}
\end{aligned}
$$


where the last equation derives from

$$
F_{k}\left(x \mid y_{k-1}\right)=\frac{F(x)^{n-k}}{F\left(y_{k-1}\right)^{n-k}}
$$

As for the case $t>y_{m-1}$, it is only possible if in the preceding auction the bidder has deviated from the equilibrium strategy and bid higher than $b_{m-1}(t)$. Given $y_{m}<y_{m-1}<t$, it does not make sense to bid above $b_{m}\left(y_{m-1}\right)$. In this case $V_{1}^{m}\left(y_{m-1}, t \mid y_{m-1}\right) \geq 0$ and so it is optimal for the bidder to bid $b_{m}\left(y_{m-1}\right)$ and win the $m$ th auction with certainty.

We now prove (6) by backward induction on $k$. For $k=m$, we have derived that given any $y_{m-1}$,

$$
V^{m}\left(t \wedge y_{m-1}, t \mid y_{m-1}\right)=\max _{z} V^{m}\left(z, t \mid y_{m-1}\right)
$$

where $t \wedge y_{k}=\min \left(t, y_{k}\right)$. Now suppose the bidder has lost the previous auctions up to the $k$ th auction for $k \leq m-1$, and observes $Y_{k-1}=y_{k-1}$. Our induction hypothesis is

$$
V^{k+1}\left(t \wedge y_{k}, t \mid y_{k}\right)=\max _{z} V^{k+1}\left(z, t \mid y_{k}\right), \forall y_{k}
$$

for the subsequent auctions $k+1, \ldots, m$. That is, if the bidder loses the $k$ th auction and observes $Y_{k}=y_{k}$, sequential rationality calls on him to bid $b_{k+1}\left(t \wedge y_{k}\right)$ in the $(k+1)$ th auction and so on. Hence, if the bidder bids now as though his type was $z$, his expected payoff equals

$$
V^{k}\left(z, t \mid y_{k-1}\right):=w\left(-b_{k}(z), t\right) F_{k}\left(z \mid y_{k-1}\right)+\int_{z}^{y_{k-1}} V^{k+1}(t \wedge y, t \mid y) d F_{k}\left(y \mid y_{k-1}\right)
$$

Differentiating yields

$$
\begin{aligned}
& V_{1}^{k}\left(z, t \mid y_{k-1}\right) \\
= & -b_{k}^{\prime}(z) w_{1}\left(-b_{k}(z), t\right) F_{k}\left(z \mid y_{k-1}\right)+\left(w\left(-b_{k}(z), t\right)-V^{k+1}(t \wedge z, t \mid z)\right) f_{k}\left(z \mid y_{k-1}\right) \\
= & w_{1}\left(-b_{k}(z), t\right) F_{k}\left(z \mid y_{k-1}\right) \\
& \times\left(\frac{w\left(-b_{k}(z), t\right)-V^{k+1}(t \wedge z, t \mid z)}{w_{1}\left(-b_{k}(z), t\right)} \frac{f_{k}\left(z \mid y_{k-1}\right)}{F_{k}\left(z \mid y_{k-1}\right)}-b_{k}^{\prime}(z)\right)
\end{aligned}
$$


Substituting $z$ for $y_{k-1}$ in 21) reveals

$$
V^{k}(z, t \mid z)=w\left(-b_{k}(z), t\right) F_{k}(z \mid z)=w\left(-b_{k}(z), t\right) \text { for all } k .
$$

So for $z \leq t, V_{1}^{k}\left(z, t \mid y_{k-1}\right) \geq 0$ and $b_{k}^{\prime}(z)>0$ imply

$$
w\left(-b_{k}(z), t\right)>V^{k+1}(t \wedge z, t \mid z)=w\left(-b_{k+1}(z), t\right)
$$

and consequently, by (23), and (11) in Appendix A,

$$
\frac{w\left(-b_{k}(z), t\right)-V^{k+1}(t \wedge z, t \mid z)}{w_{1}\left(-b_{k}(z), t\right)} \text { is nondecreasing in } t
$$

This shows that $V_{1}^{k}\left(z, t^{\prime} \mid y_{k-1}\right) \geq 0$ for all $t^{\prime}>t$. The single-crossing condition thus holds for $V^{k}\left(z, t \mid y_{k-1}\right)$ for all $z \leq t$.

For $z>t$, we show $V_{1}^{k}\left(z, t \mid y_{k-1}\right)<0$ and so it is never optimal to bid higher than the equilibrium play (which then of course implies the single-crossing condition). We have now

$$
V^{k+1}(t \wedge z, t \mid z)=V^{k+1}(t, t \mid z)>V^{k+1}(z, t \mid z)=w\left(-b_{k+1}(z), t\right), \forall z>t
$$

where the inequality is due to (20), and the equalities are due to (23) and $t<z$. Therefore, the term in large braces of 22

$$
\begin{aligned}
& \frac{w\left(-b_{k}(z), t\right)-V^{k+1}(t \wedge z, t \mid z)}{w_{1}\left(-b_{k}(z), t\right)} \frac{f_{k}\left(z \mid y_{k-1}\right)}{F_{k}\left(z \mid y_{k-1}\right)}-b_{k}^{\prime}(z) \\
< & \frac{w\left(-b_{k}(z), t\right)-w\left(-b_{k+1}(z), t\right)}{w_{1}\left(-b_{k}(z), t\right)} \frac{f_{k}\left(z \mid y_{k-1}\right)}{F_{k}\left(z \mid y_{k-1}\right)}-b_{k}^{\prime}(z) \text { by (11) } \\
\leq & \frac{w\left(-b_{k}(z), z\right)-w\left(-b_{k+1}(z), z\right)}{w_{1}\left(-b_{k}(z), z\right)} \frac{f_{k}\left(z \mid y_{k-1}\right)}{F_{k}\left(z \mid y_{k-1}\right)}-b_{k}^{\prime}(z) \\
= & 0 \text { for all } z>t \text { by }(6)
\end{aligned}
$$

Bidding $b_{k}(t)$ is therefore optimal, yielding

$$
V^{k}\left(t, t \mid y_{k-1}\right)=\max _{z} V^{k}\left(z, t \mid y_{k-1}\right), \forall y_{k-1}
$$

The first order condition $V_{1}^{k}\left(t, t \mid y_{k-1}\right)=0$ now gives

$$
b_{k}^{\prime}(t)=\frac{w\left(-b_{k}(t), t\right)-w\left(-b_{k+1}(t), t\right)}{w_{1}\left(-b_{k}(t), t\right)} \frac{f_{k}\left(t \mid y_{k-1}\right)}{F_{k}\left(t \mid y_{k-1}\right)}
$$


which, by (18), reduces to (6). Note that this also implies that for the subsequent auction, $V^{k+1}\left(t, t \mid y_{k}\right)=\max _{z} V^{k+1}\left(z, t \mid y_{k}\right), \forall y_{k-1}$. By the induction hypothesis, we conclude that $\left\{b_{k}: k=1, \ldots, m\right\}$ constitute a symmetric equilibrium for the sequential Dutch auctions.

The uniqueness of the equilibrium can be established also by induction on $k$. By the fundamental theorem of ordinary differential equations, $b_{m}$ is unique under the initial condition $b_{m}(0)=b_{0}$ because the right-hand side of (5) is continuously differentiable in $b_{m}$ and continuous in $t$ on a compact set $[0,1]$ Now suppose $b_{k+1}$ is unique. Then because $b_{k+1}(t)$ is differentiable, the right-hand side of (6) is continuously differentiable in $b_{k}$ and continuous in $t \in\left[0, y_{k-1}\right]$ so that $b_{k}$ is unique with $b_{k}(0)=b_{0}$. By induction, the uniqueness of $b_{k}$ holds therefore for all $k=1, \ldots, m$.

Finally, we verify that $b_{k}^{\prime}>0$ by backward induction. For $k=m$, let $A(t)=$ $w\left(-b_{m}(t), t\right)-u(0, t)$ so that $b_{m}^{\prime}(t)>0$ iff $A(t)>0$. We have $A(0)=0$. For $t \geq 0$, if $A(t)=0$ then $b_{m}^{\prime}(t)=0$ so that $A^{\prime}(t)=w_{2}\left(-b_{m}(t), t\right)-u_{2}(0, t)>0$ by Assumption 1. This implies $A(t)>0$ for all $t \in(0,1]$ (e.g., Hu, Matthews and Zou, 2010, Lemma $1(\mathrm{i}))$. Now suppose $b_{k+1}^{\prime}(t)>0$ on $(0,1]$ and we show $b_{k}^{\prime}>0$ on $(0,1]$. Let $B(t)=b_{k+1}(t)-b_{k}(t)$ so that by $(6), b_{k}^{\prime}(t)>0$ iff $B(t)>0$. We have $B(0)=0$. For $t>0$, if $B(t) \leq 0$ then $b_{k}^{\prime}(t) \leq 0$ so that $B^{\prime}(t)=b_{k+1}^{\prime}(t)-b_{k}^{\prime}(t) \geq b_{k+1}^{\prime}(t)>0$. This implies $B(t)>0$ on $(0,1$ ] (e.g., Matthews and Zou, 2010, Lemma 1(ii)). So by induction, $b_{k}^{\prime}>0$ on $(0,1]$ for all $k=1, \ldots, m$.

Proof of Proposition 2. We prove again the existence and uniqueness of equilibrium by backward induction on $k$. In the last period $k=m$, it is a (weakly) dominant strategy for bidder 1 with type $t$ to bid $a_{m}(t)$ according to (7). Because $w_{1}$ is continuous and positive, $a_{m}(t)$ is uniquely defined, and by Assumption 1 it's

\footnotetext{
${ }^{11}$ This is where $F(0)>0$ is useful for simplifying the uniqueness argument. If $F(0)=0$, then the differential equation has a singular point at $t=0$ but it still can be shown that the uniqueness holds in this case (e.g., see Maskin and Riley, 1984, Remark 2.1).
} 
derivative is positive:

$$
a_{m}^{\prime}(t)=\frac{w_{2}\left(-a_{m}(t), t\right)-u_{2}(0, t)}{w_{1}\left(-a_{m}(t), t\right)}>0
$$

Assuming all other active bidders play $a_{m}$ as well, the expected payoff of bidder 1 at the start of the $m$ th auction knowing $Y_{m-1}=y_{m-1}$ equals

$$
V^{m}\left(t \wedge y_{m-1}, t \mid y_{m-1}\right):=\int_{0}^{t \wedge y_{m-1}}\left(w\left(-a_{m}(y), t\right)-u(0, t)\right) d F_{m}\left(y \mid y_{m-1}\right)+u(0, t)
$$

where the notation $t \wedge y_{m-1}$ incorporates the possibility that bidder 1 has deviated from the equilibrium bid in the previous auction, resulting in $y_{m-1}<t$.

Now consider the $k$ th auction for $k \leq m-1$ assuming that a unique sequence of increasing strategies $a_{k+1}, \ldots, a_{m}$ will be played by all bidders including bidder 1 . Let $V^{k+1}\left(z \wedge y_{k}, t \mid y_{k}\right)$ denote the bidder's expected payoff if he bids in period $k+1$ as though his type was $z$. Our induction hypothesis is that for all $k \leq m-1$,

$$
\begin{aligned}
& V^{k+1}\left(t \wedge y_{k}, t \mid y_{k}\right) \\
= & \int_{0}^{t \wedge y_{k}}\left(w\left(-a_{k+1}(y), t\right)-u(0, t)\right) d F_{k+1}\left(y \mid y_{k}\right)+u(0, t) \\
\geq & V^{k+1}\left(z \wedge y_{k}, t \mid y_{k}\right) \text { for all realized } y_{k} \text { in the } k \text { th auction and } z
\end{aligned}
$$

Suppose $Y_{k-1}=y_{k-1}$ and bidder 1 is still active in the $k$ th auction. Obviously, bidding above $a_{k}\left(y_{k-1}\right)$ is weakly dominated by bidding lower than or equal to $a_{k}\left(y_{k-1}\right)$. So given that the other bidders play $a_{k}$, if bidder 1 bids as though his type was $z$, his expected payoff equals

$$
V^{k}\left(z, t \mid y_{k-1}\right)=\int_{0}^{z} w\left(-a_{k}(y), t\right) d F_{k}\left(y \mid y_{k-1}\right)+\int_{z}^{y_{k-1}} V^{k+1}(t \wedge y, t \mid y) d F_{k}\left(y \mid y_{k-1}\right)
$$

Differentiating w.r.t. $z$ gives

$$
\begin{aligned}
& V_{1}^{k}\left(z, t \mid y_{k-1}\right) \\
= & \left(w\left(-a_{k}(z), t\right)-V^{k+1}(t \wedge z, t \mid z)\right) f_{k}\left(z \mid y_{k-1}\right) \\
= & \left(w\left(-a_{k}(z), t\right)-u(0, t)-\int_{0}^{t \wedge z}\left(w\left(-a_{k+1}(y), t\right)-u(0, t)\right) d F_{k+1}(y \mid z)\right) f_{k}\left(z \mid y k_{k} 2 \Phi\right)
\end{aligned}
$$


Equation (8) implies

$$
w\left(-a_{k}(z), z\right)-u(0, z)=\int_{0}^{z}\left(w\left(-a_{k+1}(y), z\right)-u(0, z)\right) d F_{k+1}(y \mid z)
$$

If $z<t$ then the term in large braces of (28) reduces to

$$
w\left(-a_{k}(z), t\right)-\int_{0}^{z} w\left(-a_{k+1}(y), t\right) d F_{k+1}(y \mid z)
$$

which, by 13 in Appendix A, is non-negative because

$$
\begin{gathered}
\frac{w\left(-a_{k}(z), t\right)-\int_{0}^{z} w\left(-a_{k+1}(y), t\right) d F_{k+1}(y \mid z)}{w_{1}\left(-a_{k}(z), t\right)} \\
\geq \frac{w\left(-a_{k}(t), z\right)-\int_{0}^{z} w\left(-a_{k+1}(y), z\right) d F_{k+1}(y \mid z)}{w_{1}\left(-a_{k}(t), z\right)}=0 \text { by } 8
\end{gathered}
$$

If $z>t$, then the term in large braces of (28)

$$
\begin{aligned}
& w\left(-a_{k}(z), t\right)-u(0, t)-\int_{0}^{t}\left(w\left(-a_{k+1}(y), t\right)-u(0, t)\right) d F_{k+1}(y \mid z) \\
< & w\left(-a_{k}(z), t\right)-\int_{0}^{z} w\left(-a_{k+1}(y), t\right) d F_{k+1}(y \mid z) \\
\leq & 0 \text { by } 8
\end{aligned}
$$

Consequently, $V_{1}^{k}\left(t, t \mid y_{k-1}\right)=0$ is a necessary and globally sufficient condition for $a_{k}(t)$ to be optimal for bidder 1 . Since $a_{k+1}, \ldots, a_{m}$ are unique, $a_{k}(\cdot)$ is uniquely defined implicitly by (8) given $w_{1}>0$.

Finally, we show that $a_{k}(\cdot)$ is increasing by backward induction. For $k=m$ (26) shows $a_{m}^{\prime}>0$. Suppose $a_{k+1}^{\prime}>0$ and differentiate (8) to get

$$
\begin{aligned}
a_{k}^{\prime}(t)= & \frac{w_{2}\left(-a_{k}(t), t\right)-\int_{0}^{t} w_{2}\left(-a_{k+1}(y), t\right) d F_{k+1}(y \mid t)}{w_{1}\left(-a_{k}(t), t\right)} \\
& +(n-k) \frac{f(t)}{F(t)}\left(\frac{w\left(-a_{k}(t), t\right)-w\left(-a_{k+1}(t), t\right)}{w_{1}\left(-a_{k}(t), t\right)}\right)
\end{aligned}
$$

By (8) and (14), the first term on the right-hand side is non-negative. Since $a_{k+1}^{\prime}>0$ as assumed, (8) implies $a_{k}(t)<a_{k+1}(t)$. Hence the last term in the above expression is positive. The conclusion of the proposition is thus established by induction. 
Proof of Proposition 3. Dutch auctions. We show that (i)-(iii) follow from (15) in Appendix A, because (6) and $F_{k}\left(x \mid y_{k-1}\right)=F(x)^{n-k} / F\left(y_{k-1}\right)^{n-k}$ imply

$$
\begin{aligned}
b_{k}^{\prime}(t) & =\frac{w\left(-b_{k}(t), t\right)-w\left(-b_{k+1}(t), t\right)}{w_{1}\left(-b_{k}(t), t\right)} \frac{f_{k}\left(t \mid y_{k-1}\right)}{F_{k}\left(t \mid y_{k-1}\right)} \\
& >[\leq]\left(b_{k+1}(t)-b_{k}(t)\right) \frac{f_{k}\left(t \mid y_{k-1}\right)}{F_{k}\left(t \mid y_{k-1}\right)} \text { if } w_{11}<[\geq] 0
\end{aligned}
$$

The risk neutral case (ii) is well known. Now we show Case (i) assuming that $w_{11}<0$. Rearranging terms of the first inequality in 30 gives

$$
\frac{d}{d t}\left[b_{k}(t) F_{k}\left(t \mid y_{k-1}\right)\right]>b_{k+1}(t) f_{k}\left(t \mid y_{k-1}\right)
$$

For $t=y_{k+1}$, integrating over $\left[0, y_{k}\right]$ yields

$$
\begin{aligned}
b_{k}\left(y_{k}\right) & >\frac{1}{F_{k}\left(y_{k} \mid y_{k-1}\right)} \int_{0}^{y_{k}} b_{k+1}\left(y_{k+1}\right) d F_{k}\left(y_{k+1} \mid y_{k-1}\right) \\
& =\frac{1}{F^{n-k}\left(y_{k}\right)} \int_{0}^{y_{k}} b_{k+1}\left(y_{k+1}\right) d F^{n-k}\left(y_{k+1}\right) \\
& =E\left(b_{k+1}\left(Y_{k+1}\right) \mid Y_{k+1}<y_{k}\right) \\
& =E\left(\tilde{b}_{k+1} \mid b_{k}\left(y_{k}\right)\right)
\end{aligned}
$$

In the Dutch auction, $p_{k}=b_{k}\left(y_{k}\right)$. So we have shown that $w_{11}<0$ implies $E\left(\tilde{p}_{k+1} \mid p_{k}\right)<$ $p_{k}$. Case (iii) can be established by simply altering the sign of the inequality, and so is omitted.

Vickrey auctions. By (8), we have

$$
w\left(-a_{k}\left(y_{k}\right), y_{k}\right)=\int_{0}^{y_{k}} w\left(-a_{k+1}(y), y_{k}\right) d F_{k+1}\left(y \mid y_{k}\right)
$$

This shows that for $w\left(\cdot, y_{k}\right)$, the payment $a_{k}\left(y_{k}\right)$ is the certainty equivalent of random payment $a_{k+1}(y)$, under expectation according to distribution $F_{k+1}\left(y \mid y_{k}\right)$. Therefore,

$$
a_{k}\left(y_{k}\right)\left\{\begin{array}{l}
>\int_{0}^{y_{k}} a_{k+1}(y) d F_{k+1}\left(y \mid y_{k}\right) \text { for } w_{11}<0 \\
=\int_{0}^{y_{k}} a_{k+1}(y) d F_{k+1}\left(y \mid y_{k}\right) \text { for } w_{11}=0 \\
<\int_{0}^{y_{k}} a_{k+1}(y) d F_{k+1}\left(y \mid y_{k}\right) \text { for } w_{11}>0
\end{array}\right.
$$


Since $a_{k}\left(y_{k}\right)$ and $y_{k}$ are one-to-one, we obtain

$$
p_{k}=a_{k}\left(y_{k}\right)\left\{\begin{array}{l}
>\int_{0}^{y_{k}} a_{k+1}(y) d F_{k+1}\left(y \mid y_{k}\right)=E\left(\tilde{p}_{k+1} \mid p_{k}\right) \text { for } w_{11}<0 \\
=\int_{0}^{y_{k}} a_{k+1}(y) d F_{k+1}\left(y \mid y_{k}\right)=E\left(\tilde{p}_{k+1} \mid p_{k}\right) \text { for } w_{11}=0 \\
<\int_{0}^{y_{k}} a_{k+1}(y) d F_{k+1}\left(y \mid y_{k}\right)=E\left(\tilde{p}_{k+1} \mid p_{k}\right) \text { for } w_{11}>0
\end{array}\right.
$$

\section{References}

Arrow, Kenneth J. 1951. "Alternative Approaches to the Theory of Choice in Risk-Taking Situations." Econometrica, 19: 404-437.

Ashenfelter, Orley. 1989. "How Auctions Work for Wine and Art." Journal of Economic Perspectives, 3: 23-36.

Ashenfelter, Orley, and David Genesove. 1992. "Testing for Price Anomalies in Real-Estate Auctions." American Economic Review, 82: 501-505.

Athey, Susan. 2001. "Single Crossing Properties and the Existence of Pure Strategy Equilibria in Games of Incomplete Information." Econometrica, 69: 861889.

Athey, Susan. 2002. "Monotone Comparative Statics Under Uncertainty." Quarterly Journal of Economics, 117: 187-223.

Beggs, Alan, and Kathryn Graddy. 1997. "Declining Values and the Afternoon Effect: Evidence from Art Auctions." Rand Journal of Economics, 28: 544565.

Bernhardt, Dan, and David Scoones. 1994. "A Note on Sequential Auctions." American Economic Review, 84: 501-505. 
Black, Jane, and David de Meza. 1992. "Systematic Price Differences Between Successive Auctions Are No Anomaly." Journal of Economics and Management Strategy, 1: 607-28.

Board, Simon. 2007. "Bidding into the red: a model of post-auction bankruptcy." Journal of Finance 62, 2696-2723.

Chanel, Oliver, Louis-Andre Gérard-Varet, and Stephanie Vincent. 1996. "Auction Theory and Practice: Evidence from the Market for Jewelry," in Economics of the Arts: Selected Essays. Victor Ginsburgh and Pierre-Michel Menger, eds. Amsterdam: Elsevier, pp. 135-49.

Deltas, George, and and Georgia Kosmopoulou. 2004. "Catalogue' vs 'Order-ofsale' effects in Sequential Auctions: Theory and Evidence from a Rare Book Sale. Economic Journal, 114: 28-54.

DeMarzo, Peter M., Ilan Kremer, and Andrzej Skrzypacz. 2005. "Bidding with Securities: Auctions and Security Design." American Economic Review, 95: 936-959.

Engelbrecht-Wiggans, Richard. 1994. "Sequential Auctions of Stochastically Equivalent Objects." Economics Letters, 44: 87-90.

Engelbrecht-Wiggans, Richard, and Charles M. Kahn. 1999. "Calibration of a Model of Declining Prices in Cattle Auctions." Quarterly Review of Economics and Finance, 39: 113-128.

Eso, Peter, and Lucy White. 2004. "Precautionary Bidding in Auctions." Econometrica, 72: 77-92.

Gale, Ian L., and Donald B. Hausch. 1994. "Bottom-Fishing and Declining Prices in Sequential Auctions." Games and Economic Behavior, 7: 318-331. 
Gale, Ian L, and Mark Stegeman. 2001. "Sequential Auctions of Endogenously Valued Objects." Games and Economic Behavior, 36: 74-103.

Gandal, Neil. 1997. "Sequential Auctions of Interdependent Objects: Israeli Cable Television Licences." Journal of Industrial Economics, 45: 227-44.

Ginsburgh, Victor A. 1998. "Absentee Bidders and the Declining Price Anomaly in Wine Auctions." Journal of Political Economy, 106: 1302-1319.

Holt, Charles A. 1980. "Competitive Bidding for Contracts under Alternative Auction Procedures." The Journal of Political Economy, 88: 433-445.

Hu, Audrey, Steven A. Matthews, and Liang Zou. 2010. "Risk Aversion and Optimal Reserve Prices in First and Second-Price Auctions." Journal of Economic Theory 145: 1188-1202.

Hu, Audrey, Steven A. Matthews, and Liang Zou. 2014. "English Auctions with Ensuing Risk and Heterogeneous Bidders." Working Paper.

Hu, Audrey, Theo Offerman, and Liang Zou. 2014. "How Risk Sharing May Enhance Efficiency in English Auctions." Tinbergen Institute Discussion Paper, TI 2014-015/I.

Jeitschko, Thomas D., and Elmar Wolfstetter. 1998. "Scale Economies and the Dynamics of Recurring Auctions." Economic Inquiry, 40: 403-14.

Jones, Chris, Flavio M Menezes, and Francis Vella. 2004. "Auction Price Anomalies: Evidence from Wool Auctions in Australia." Economic Record, 80: 271288.

Jewitt, Ian. 1987. "Risk Aversion and the Choice between Risky Prospects: The Preservation of Comparative Statics Results." Review of Economic Studies, LIV: 73-85. 
Krishna, Vijay. 2002. Auction Theory. San Diego, London and Sydney: Elsevier Science, Academic Press.

Kittsteiner, Thomas, Joerg Nikutta, and Eyal Winter. 2004. "Declining Valuations in Sequential Auctions." International Journal of Game Theory, 33: 89-106.

Maskin, Eric, and John Riley. 1984. "Optimal Auctions with Risk Averse Bidders." Econometrica, 52: 1473-1518.

Matthews, Steven A. 1987. "Comparing Auctions for Risk Averse Bidders: A Bidder's Point of View." Econometrica, 55: 633-646.

Menezes, Flavio M. and Monteiro, Paulo K. 2003. "Synergies and Price Trends in Sequential Auctions." Review of Economic Design, 8: 85-98.

Mezzetti, Claudio. 2011. "Sequential Auctions with Informational Externalities and Aversion to Price Risk: Decreasing and Increasing Price Sequences." Economic Journal, 121: 990-1016.

McAfee, R. Preston, and Daniel Vincent. 1993. "The Declining Price Anomaly." Journal of Economic Theory, 60: 191-212.

McAfee, R. Preston, and Daniel Vincent. 1997. "Sequentially Optimal Auctions" Games and Economic Behavior, 18: 246-276.

Milgrom, Paul. 2004. Putting Auction Theory to Work. Cambridge: Cambridge University Press.

Milgrom, Paul, and Robert J. Weber. 1982. "A Theory of Auctions and Competitive Bidding." Econometrica, 50: 1089-1122.

Milgrom, Paul, and Robert J. Weber. 2000. "A Theory of Auctions and Competitive Bidding II," in The Economic Theory of Auctions Vol. II. Klemperer Paul. ed. Edward Elgar Publishing Ltd, pp. 179-194. 
Milgrom, Paul, and Chris Shannon. 1994. "Monotone Comparative Statics." Econometrica, 62: 157-180

Pitchik, Carolyn, and Andrew Schotter. 1988. "Perfect Equilibria in BudgetConstrained Sequential Auctions: An Experimental Study." RAND Journal of Economics, 19: 363-388.

Pratt, John. W.1964. "Risk Aversion in the Small and in the Large." Econometrica, 32: 122-136.

van den Berg, Gerard. J., Jan C. van Ours, and Menno P. Pradhan. 2001. "The Declining Price Anomaly in Dutch Dutch Rose Auctions." American Economic Review, 91: 1055-62.

Weber, Robert J. 1983. "Multi-Object Auctions." in Auctions, Bidding and Contracting: Uses and Theory. Richard Engelbrecht-Wiggans, Martin Shubik, and Robert M. Stark, eds. New York: New York University Press, pp. 165-194.

Zheng, C., 2001. "High bids and broke winners." Journal of Economic Theory 100, $129-171$. 